\title{
Deriving full repetition in Blackfoot with additive focus*
}

\author{
Meagan Louie \\ The University of British Columbia
}

\begin{abstract}
I argue that Blackfoot's method of marking repetition, mattsista'- consists of two morphemes, matt- and ista'-. While both encode an additional event, matt-'s event is restricted only to being a focus alternative to the asserted event, leaving predicate identity and temporal precedence to be encoded by ista'-. I propose that ista'-'s event variable requires a linguistically encoded antecedent which matt-'s event acts as, deriving the fact that mattsista'- has a focus-sensitive interpretation.
\end{abstract}

Keywords: semantics, pragmatics, repetition, focus, Blackfoot

\section{Introduction}

In this paper I investigate how Blackfoot (Plains Algonquian) encodes repetition. By "repetition," I refer to the meaning encoded by English words like again, as in (1). Where the prejacent in (1) "I ran" indicates a running event, $e$, by the speaker, "again" indicates that there was some other event, $e^{\prime}$, which temporally preceded the asserted event, where both $e$ and $e^{\prime}$ have the property of being running events by the speaker (cf. Dowty 1979; Fabricius-Hansen 2001; von Stechow 1996; Beck 2006).

\section{(1) I ran again}

The way Blackfoot encodes this sort of meaning is illustrated in (2). Like English, the Blackfoot utterance has a prejacent part nit-okska'si which means "I ran", and repetition (i.e., temporal precedence and an identical property condition between e' and e) is encoded by what Frantz \& Russell (1989) gloss as a single morpheme meaning "again", mattsista'-.

* Thanks to R-M Déchaine, L. Matthewson and H. Davis; M. Wiltschko, S. Armoskaite, H. Bliss, J. Dunham, A. Reis Silva, A. Scott, LING 530A\&B (Focus\&Pragmatics), especially M. Rochemont and H. Rullmann, and helpful commenters at SALT 2010: J. Tonhauser, S. Murray, A. McKenzie. I am most indebted to B. Bullshields, for sharing with me not only her language, but also her insightful comments. Nitsííkohtaahsi'taki! 
Meagan Louie

(2)

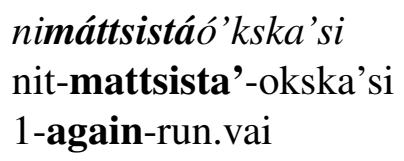

nimáttsistáó'kska'si nit-mattsista'-okska'si 1-again-run.vai

'I ran again.' ${ }^{1}$

At first glance mattsista'- and again appear parallel, but whereas English again is felicitous in either a repetitive or restitutive context, restitutive readings for Blackfoot mattsista'- are strongly focus-sensitive, only being available in agent-focus contexts.

My main claim is that mattsista'- consists of two morphemes: matt- and ista'-, where the markedness of the restitutive reading can be compositionally derived. I show that matt- is typically interpreted as additive VP-focus, ${ }^{2}$ presupposing that the agent of the asserted event also participated as agent of another salient event, and suggest that $i s t a$ '- encodes the temporal precedence and identity condition associated with English again. I propose that ista'- has stricter requirements than again, however, as to how its anaphoric dependency must be satisfied: while the event referred to by again may be extralinguistically supplied via context, the denotation of ista' - includes an event variable that must obtain its reference from a linguistically encoded event. I suggest that the event associated with matt- satisfies this local dependency, such that the events presupposed by matt- and ista'- are identified as the same event, and then show how this, along with default VP-focus, derives the consequence that matt- and ista'- together require a fully repetitive interpretation. In the remainder of section 1 , I provide background on the repetitive/restitutive ambiguity, then show that Blackfoot mattsista'- appears to lack this ambiguity. In section 2, I provide evidence that mattsista'- is morphologically complex. In section 3, I propose denotations for matt- and ista'-, and show how these compositionally combine to derive the lack of ambiguity seen in section section 1 . In section 4 , I address consequences for analysis, regarding non-default focal contexts. In section 5, I conclude.

1 Glosses: vai/vii= (in)animate intransitive verb, vta/vti=transitive (in)animate verb, 1,2=1st/2nd person, 3=3rd proximate, $3^{\prime}=3$ rd obviative, $0=$ inanimate, loc=local person ( 1 st or 2 nd), $X>Y=X$ acts on $Y$, inv=inverse (X acts on $Y$, $Y$ outranks $X$ on person-animacy hierarchy: 2,1 $>3>3$ ' $>0$ ), rl=relative root, $\mathrm{sbj}=$ subjunctive, $\mathrm{cj}=$ conjunctive, $\mathrm{conj}=$ "and/but", impf=imperfective, $\mathrm{perf}=$ perfect, fut=future, caus $=$ causative, ints=intensifier, neg=negation, nonaff=non-affirmative, recip=reciprocal, $n . f a c t=$ nonfactive, $\mathrm{dtp}=$ distinct third person, $\mathrm{y} / \mathrm{n}=$ yes/no $\mathrm{Q}, \mathrm{dem}=$ demonstrative, $\mathrm{pl}=$ plural, $\mathrm{sg}=$ singular, $\exp =$ expletive, $\mathrm{ic}=$ initial change (morphononological process). Blackfoot data, unless otherwise marked, is from author's fieldwork notes, organized/marked by (Consultant:YYYY-MM-DD)

2 Note that when I use the term "VP," I do so under the assumption that agents are introduced VPexternally, in the sense of Kratzer 1996 
Deriving full repetition in Blackfoot

\subsection{The repetitive/restitutive ambiguity}

English again is a presuppositional element requiring some event, which matches the asserted event's properties, to have temporally preceded the asserted event. The presupposition is often characterized as ambiguous, however, in that it may be satisfied in more than one way - either repetitively, or restitutively (cf. Dowty 1979; Fabricius-Hansen 2001; von Stechow 1996; Beck 2006). The readings are illustrated below, where the utterance in (3) can either presuppose (a) that I opened the door before (the fully repetitive reading), or (b) that the door was open before (the restitutive reading).

(3) I opened the door again

a. Repetitive: I opened that door when I came in, but the wind blew it shut. So I opened the door again

b. Restitutive: That door was already open when I came in, but the wind blew it shut. So I opened the door again

The distinction thus corresponds to whether the entire asserted event is a repetition of the presupposed event (the repetitive reading), or whether it is just the the result state of the asserted event that is a repetition of the presupposed event (the restitutive reading).

There are two main approaches to capturing this ambiguity theoretically. The structural account (cf. von Stechow 1996) argues that there is one lexical entry for again, but that predicates like open are syntactically decomposable into an empty agentive $v$, and a result state. When again adjoins to a phrase structure encoding just the result state, prior to the merge of $v$, the restitutive meaning is derived. When again adjoins after $v$ has merged, i.e., when it adjoins to a phrase structure that encodes an event corresponding to [cause [result state]], the fully repetitive meaning is derived.

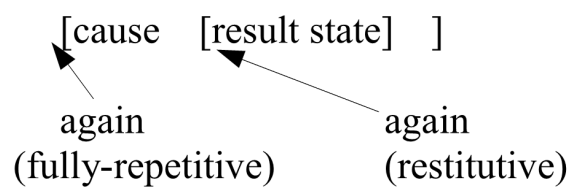

The lexicalist account (cf. Dowty 1979) avoids positing syntactic decomposition and instead posits lexical ambiguity for again, such that it consists of two lexemes, again1 and again2; one lexeme corresponds to the restitutive meaning, the other to the repetitive meaning. ${ }^{3}$

3 See von Stechow 1996 for a criticism of Dowty's meanings for again1 and again2, as well as a criticism of Fabricius-Hansen's (2001) repetitive and counter-directional again. 
Meagan Louie

\subsection{Blackfoot mattsista'- lacks restitutive readings}

Unlike English again, Blackfoot mattsista'- at first appears incompatible with restitutive readings. (4a) shows its felicity in a fully-repetitive context. (4b) shows its infelicity in a restitutive context. ${ }^{4}$

(4) nimáttsistá'kowai'piksíp (I opened it again)

a. Repetitive: omi kitsím nitsíkowai'piksíp, nitáitsipissi

omi kitsim nit-ikowai'piksi-'p nit-á-it-ipi-ssi

dem door 1-open-loc $>0$ 1-impf-rl-enter-cj

itsohkohpápoka. ki nimatts(it)sistai'kowai'piksíp

it-yohkohpápoka ki ni-matt-(it)-ista'-ikowai'piksi-'p

rl-blow.shut conj 1-add-(rl)-again-open.vti-loc $>0$

'I opened that door when I went in, but then it blew shut.

And (then) I opened it again.'

(BB:2010-04-16)

b. Restitutive: omi kitsím íkaikowaistsii, nitáitsipissi

omi kitsim iikaa-ikowaistsii nit-á-it-ipi-ssi

dem door perf-open.vii 1-impf-rl-enter-cj

itsohkohpápoka. \#ki nimatts(it)sistai'kowai'piksíp

it-yohkohpápoka ki ni-matt-(it)-ista'-ikowai'piksi-'p

rl-blow.shut conj 1-add-(rl)-again-open-loc $>0$

'That door was already open when I went in, then it blew shut.

\# And (then) I opened it again.'

(BB:2010-04-16)

This generalisation is robust; (5) shows a context where a restitutive presupposition is satisfied, but a mattsista'-marked utterance is nonetheless rejected.

(5) Context: Last year, Solveiga caught Abigail, a criminal. Then she escaped prison, but yesterday, I caught her again.

$\begin{array}{lll}\text { \#nimáttsistáyinimata } & \text { ana } & \text { Abigail } \\ \text { ni-matt-ista'-yinniM-at-a } & \text { an-wa } & \text { Abigail } \\ \text { 1-add-again-catch.vta-?-loc }>3 & \text { dem-3 } & \text { abigail }\end{array}$

'I caught Abigail again.'

(BB:2009-03-10)

BB comment: That means YOU caught her before, you caught her twice.

4 Note that in anticipation of my analysis, I will gloss matt- as "add(itive)," and ista'- as "again.' Except in cases where I am entertaining the possibility that mattsista'- is a single morpheme, in order to argue against it. 
Deriving full repetition in Blackfoot

The question is how to account for this generalisation. Adopting a structural account, we could stipulate that mattsista'- is unable to merge in a position where it only scopes over a result state. Adopting a lexical view, we could assume that Blackfoot mattsista' - corresponds to the English repetitive again, and that Blackfoot lacks a lexical item corresponding to restitutive again. I argue that neither of these possibilities account for the full-picture, as both fail to acknowledge my main empirical claim- the claim that mattsista'- is compositionally complex, consisting of two morphemes matt- and ista'-. In the following section, I provide morphological evidence for this claim.

\section{Evidence for mattsista'-'s complexity}

\subsection{Other morphemes can intervene between matt- and ista'-}

The first piece of evidence for the proposed decomposition is shown in (6)-(8), where we see that other morphemes can occur inside mattsista'- intervening between mattand ista'-. In (6) the ability modal ohkott- intervenes, in (7), the imperfective $a^{-}$ intervenes, in (8), the "means" linker ooht- intervenes. ${ }^{5}$

(6) nitáákattohkottsista'sai'notok

nit-áák-matt-ohkott-ista'-áásei'n-oto-k

1-fut-add-able-again-cry.vai-caus-inv

'She will be able to make me cry again.'

(BB:2008-11-03)

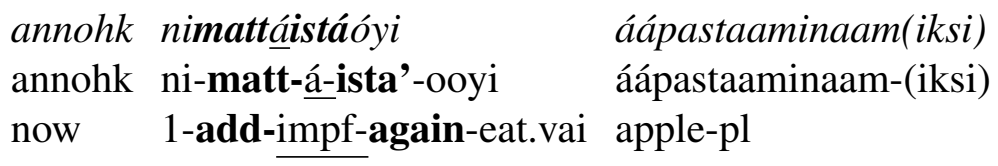

(BB:2009-02-19)

(8) nimáttoohtsistayistsini'p isttowan

ni-matt-ooht-ista'-yistsini-'p isttowan

1-add-means-again-cut.vti-loc $>0$ knife

'I cut it again with a knife.'

(BB:2009-02-23)

\section{2 matt- can appear independently}

The second piece of evidence for mattsista'-'s complexity is that matt- can occur independently, which is what we predict if mattsista'- is indeed composed

5 Recall also, that the relative root it- "then" intervenes between matt- and ista'-, as seen in example (4). 
of separate morphemes. Frantz \& Russell's (1989) dictionary glosses matt- as "again/additionally"; in my fieldwork I find that matt- most consistently corresponds to an additive VP-focusing "also/too", being used in contexts where the agent of the event is presupposed to be participating (or have participated) as the agent of some other event (9).

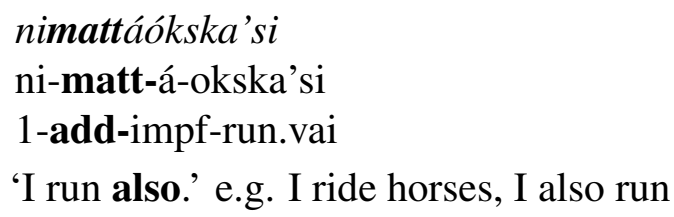

(BB:2009-03-10)

\section{3 matt- and mattsista'- are in complementary distribution}

The third piece of evidence indicating that mattsista'- contains the morpheme mattis that the two forms cannot co-occur. This is shown in (10-11), where the consultant was given a felicitous English utterance with both also and again, and asked to translate into Blackfoot. In all cases, the consultant offered the (a) examples, containing only matt( $s$-)ista'-. The elicitor then offered the constructed examples in (b), with matt- to contribute the meaning of also and a full-form mattsista'to contribute the meaning of again, however these constructed utterances were categorically rejected.

(10) Target: I ran again, and I also jumped again.

a. nimáttsistókska'si $k i \quad$ nimattsistá'sspohpai'pi ni-matt-ista'-okska'si ki ni-matt-ista'-ssp-ohpai'pi 1-add-again-run.vai conj 1-add-again-up-jump.vai 'I ran again, and I jumped again.'

b. *nimáttsistókska'si ki nimattattsistá'sspohpai'pi ni-matt-ista'-okska'si ki ni-matt-mattsista'-ssp-ohpai'pi 1-add-again-run.vai conj 1-add-again-up-jump.vai Target: I ran again, and I also jumped again.

(11) Target: She will dance again, and she will also sing again

a. áákattsistaiîhpiyi $\quad k i \quad$ áákattsistai'inihki áák-matt-ista'-ihpiyi ki áák-matt-ista'-inihki fut-add-again-dance.vai conj fut-add-again-sing.vai 'She is gonna dance again, and she is gonna sing again 
Deriving full repetition in Blackfoot

$\begin{array}{lll}\text { b. } \quad \text { *áákattsistaiíhpiyi } & k i & \text { áákattattsistai'inihki } \\ \text { áák-matt-ista'-ihpiyi } & \mathrm{ki} & \text { áák-matt-mattsista'-inihki } \\ \text { fut-add-again-dance.vai } & \text { conj } & \text { fut-add-again-sing.vai }\end{array}$

Target: She will dance again, and she will also sing again.

(BB:2010-04-01)

This complementary distribution is expected if mattsista'-consists of matt-and ista'-; it would require a separate explanation if matt- and mattsista'- were unrelated. Note that while matt- is sometimes compatible with a translation as "again," as suggested by Frantz \& Russell's (1989) gloss, matt- is not merely a short-form, or fast-speech variant of mattsista'-, as they have different semantic properties: while mattsista'- necessarily imposes a temporal ordering on the presupposed and asserted event, as shown in (12), this is not the case for matt-. This is shown in (13), where the matt- marked asserted event need not temporally follow the presupposed event.

\#anihk nitsspiyi ki matonni nimattsistai'ihpiyi anihk nit-ihpiyi ki matonni ni-matt-ista'-ihpiyi earlier.today 1-dance.vai and yesterday 1-add-again-dance.vai

'I danced today, and I danced yesterday also/ \# again.'

(BB:2009-05-05)

(13) Context: In the morning, I[S2] made cookies (e). In the afternoon, I baked a pie $\left(e^{\prime}\right)$. My neighbour[S1] visits and asks:

S1: "Did you bake that pie?"

$\mathrm{S} 2: \quad a ́ a ́, \quad k i \quad$ omistsi pisatskiitaanists nimattsskiitatoopyaa áá, ki om-istsi pisat-ihkiitaan-istsi ni-matt-ihkiitaatoo-'p-yaa yes, conj dem-pl fancy-bake-0pl 1-add-bake.vti-loc $>0-3 \mathrm{pl}$ "Yes, and I also baked those cookies."

(BB:2010-03-15)

Recall too that the repetitive meaning associated with English again consisted not only of a temporal precedence requirement, but also an identical property condition. The data below shows that while mattsista'-, like again, encodes an identical property condition (as indicated by the consultant's comments in (14)), matt- does not (as shown by matt-'s felicity in example (15)). 
(14)

$P=$ freezing,$P^{\prime}=$ freezing, freezing $=$ freezing

matonni mattsista'kokoto omi isstonnikis

matonni matt-ista'-iko'koto-wa om-yi isstonniki-s

day.before add-again-freeze.vii-3 dem-0 ice-cream-?

'Yesterday the ice-cream froze again.'

(BB:2009-03-10)

BB Comment: It's like the ice-cream froze before, melted, and then now it's freezing again

(15) $P=$ singing, $P^{\prime}=$ dancing, singing $\neq$ dancing

ana Heather kámínihkisi áákattsspiyi

ana Heather kam-inihki-si áák-matt-ihpiyi

dem Heather if-sing.vai-sbj:3 fut-add-dance.vai

'If Heather sings, she will also dance.'

(BB:2010-03-24)

With these observations, in the following section I posit denotations for matt- and ista'-. I then show how these denotations combine to derive mattsista'-'s apparent incompatibility with restitutive contexts.

\section{Composing mattsista'-}

\subsection{A semantics for Blackfoot matt-}

Recall that Frantz \& Russell (1989) gloss matt- as "again" or "additionally," and that in my fieldwork, matt- most often corresponds to an additive VP-focusing "also" or "too." The basic analyses for English "again" and the additive focus particles "also" and "too" are given in (16) and (17). (16) states that again presupposes that in addition to the asserted event, $e$, there exists a previous event, $e^{\prime}$, where the event predicate, $P$, which is being asserted of $e$, also holds for $e^{\prime}$.

\section{(16) Lexical Entry for again}

Let $P$ be a property of eventualities and let $e$ be an eventuality. $\llbracket$ again $\rrbracket(P)(e)$ is defined only if $\exists e^{\prime}\left[\llbracket \operatorname{MAX} \rrbracket(P)(e)=1 \wedge e^{\prime}<_{t} e\right]$. Where defined, \again $\rrbracket(P)(e)=1$ iff $P(e)=1$. (cf. von Stechow 1996: 95) ${ }^{6}$

6 The inclusion of a MAX operator in the denotation ensures that we do not just indicate a continuing event, i.e., cases where we would use still. $\llbracket \mathrm{MAX} \rrbracket(P)(e)=1$ iff $P(e)$ and there is no $e^{\prime}$ such that $e$ is a proper subpart of $e^{\prime}$ and $P\left(e^{\prime}\right)=1$. (von Stechow 1996). 
Deriving full repetition in Blackfoot

\section{(17) Lexical Entry for also/too}

Let $\llbracket \alpha \rrbracket^{o}=p, C=$ the context $\llbracket a l s o \rrbracket(p)$ only defined if $C$ provides $p, p^{\prime} \in \llbracket \alpha \rrbracket^{F}, p^{\prime} \neq \llbracket \alpha \rrbracket^{o}, \& p^{\prime}(w)=1$

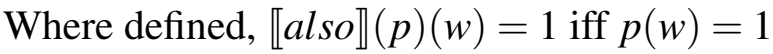

(cf. Rooth 1992; Karttunen \& Peters 1979)

As focus alternatives describe events which match the asserted event's properties, taking into account abstraction over focus-marked elements, also, like again, presupposes that there exists some event which matches the asserted event according to some property. For again, this is the property of events attributed to the asserted event; for also this is the focus-abstracted property that all of the focus-alternatives have in common. Since matt- is most often translated as also or again; this suggests that matt-'s core semantics indicates that in addition to the asserted event, $e$, a presupposed event $e^{\prime}$, occurred (or occurs), where $e$ and $e^{\prime}$ share some property. Note, however, that matt- is not always translated as also or again. In many cases, matt- is not translated at all. Consider the minimal pair in (18); (18a) is marked with the additive agent-focus marker noohkatt- ${ }^{7}$; its offered English translation correspondingly contains an "also." In contrast, (18b) is only marked with matt-; its offered English translation lacks an overt element encoding whatever semantic import matt- may contribute.
a. oma imitaa íkohpokimi, ki oma poos iikoohkattohpokimi oma imitaa iik-ohpokimi ki oma poos iik-noohkatt-ohpokimi dem dog ints-small.vai and dem cat ints-also-small.vai 'That dog is small, and that cat is small also.'

b. oma imitaa íkohpokimi ki oma poos iikattohpokimi oma imitaa iik-ohpokimi $\mathrm{ki}$ oma poos iik-matt-ohpokimi dem dog ints-small.vai and dem cat ints-add-small.vai 'That dog is small, and that cat is small.'

BB comment:"[This one is] without the 'also' - ikoohkatt- is 'also'. It's like you're looking at a cat and you're looking at a bowl, and they're both small, without the 'also"”

(BB:2010-02-08)

7 Whereas matt- is generally used for additive VP-focus, noohkatt- is generally used for additive agent-focus. There is evidence that noohkatt, like mattsista'-, is complex, consisting of a morpheme noohk- as well as additive matt-. I leave this for further research. 
Consider also the data provided by the exchange between elicitor (ML) and consultant (BB) in (19). When produced out-of-the-blue, utterances with matt- are infelicitous, shown in (19a), unless matt- is purposely used to flout Grice's Maxim of Quantity, ${ }^{8}$ in order to shock the addressee into asking clarifying questions and thus open up a conversation. This is suggested by the consultant's comments in (19b), and the exchange of comments between elicitor and consultant in (19c).

a. ML: \#nimáttsistohkohpi ni-matt-istokohpi

1-add-fall.down.vai

Target: I also fell down

BB: That's not good. Well, that's like if you're telling a story, e.g. telling your friend $(19 b)$

b. $\quad$ BB: kei má, nimáttsistohkohpi

kei ma, ni-matt-istohkohpi

exp exp, 1-add-fall.down.vai

"Holy, I fell down!"

BB: Like an opening for a conversation, so the person you're talking to will ask you "what happened to you? How did you fall?" So you can tell more about what happened.

c. ML: And if I say kei má, nitsistohkohpi ?

kei ma, nit-istohkohpi

$\exp \exp , 1$-fall.down.vai

BB: "Holy, I fell down"

BB: "Holy, I fell down." You know what happened to me? I fell. I went and fell.

ML: So if you just say nitsistohkohpi it doesn't open up the conversation like nimáttsistohkohpi?

BB: Yeah.

(BB:2010-01-27)

8 This can be viewed as a violation of Grice's Maxim of Quantity. matt- presupposes that both SAPs are aware of some event, $e^{\prime}$, that is somehow related to the asserted event. Uttering a matt-marked utterance out-of-the-blue is thus less informative than is required for the purposes of the conversation, as the Addressee will be left unaware of what event, $e^{\prime}$, the asserted event is meant to stand in relation to. Pat Littell suggested this interpretation of the exchange in (19) to me. 
Deriving full repetition in Blackfoot

This use of matt- indicates that the asserted event is part of a set of events, however the members of this set may be connected in terms of their temporal precedence, or their contribution to a story, and need not be characterized as a set of events which are connected because each member shares a common property. ${ }^{9}$ Taking these data into account, I propose that matt- has a broader meaning than either again or also, such that it merely presupposes that the asserted event is a member of a (non-singleton) partially-ordered set of events, the identity of which is contextually resolved. This is in (20):

\section{(20) Lexical Entry for matt-}

Let $e$ be the asserted event, $E$ be a set of partially ordered events (available in the context), and $e^{\prime \prime}$ be a contextually-salient event. Then,

$$
\llbracket \text { matt }-\rrbracket^{e^{\prime \prime}, E}={ }_{\lambda P_{<l,<s, t>>} \lambda e \lambda w:\left[e \in E \& e^{\prime \prime} \in E \& e^{\prime \prime} \neq e \& e^{\prime \prime} \leq_{\mathrm{p}} w\right] . P(e)(w)}
$$

So matt- presupposes that the asserted event, $e$, is a member of a poset of events, $E$, where at least one member of $E$, call it $e^{\prime \prime}$, is a part of the actual world. In the basic case, where matt- is interpreted as additive VP-focus also/too, $E$ is taken to be the set derived by applying the sum operation over the set of events in which the Agent of the asserted event, $e$, participated as agent. I suggest that this resolution of $E$ is an artifact of basic pragmatic principles, i.e., that in default elicitation contexts, with no previous information structure present, one assumes that the agent of the asserted event maps onto the topic/protagonist of discourse, whose adventures we follow. This sets up a context where the discourse is expected to consist of utterances describing different actions by the agent- the set of events which exemplify a VPfocus p-set. Assuming an algebraic view of events (cf. Bach 1986; Bonomi \& Casalegno 1993; Krifka 1989), this set of events can then be extended by the sum relation to create a superset which is partially ordered by the part-of relation. In the cases where matt- is interpreted as again, E corresponds to the poset of events derived by applying the sum operation over the set of events exemplifying the VPdenotation. In the broadest case, such as in (18) and (19), $E$ can be taken as a set of events described in a temporally ordered discourse/narrative.

9 Although perhaps the use in (19) could be construed of as referring to a set of events with the abstract property "contributing-to-story-X." I leave for further speculation the issue of whether the all of the events in the set that matt- makes reference to must be characterised by a common property. If so, the data in (19) would seem to indicate that the common property need not a linguistic representation, but can be purely pragmatic. 
Meagan Louie

\subsection{A semantics for Blackfoot ista'-}

Recall the prediction that if mattsista'- consists of matt- and ista'-, then matt- and ista'- should occur independently. This was the case for matt-, however (21) shows that ista'- always requires matt- in order to be used grammatically:

a. *nitsistá'oyi

nit-ista'-ooyi

1-again-eat.vai

Target: I ate again

(BB:2009-02-19)

BB Comment: short form of nimattsistá'oyi, but not good Blackfoot. You're leaving bits out

b. anahk Amelia istai'ihpiyi

anahk Amelia ista'-ihpiyi-wa

dem Amelia again-dance.vai-3

Target: Amelia danced again

(BB:2009-03-23)

c. *anáhk amelia ista'wáásai'ni

anahk Amelia ista'-waasai'ni-wa

dem Amelia again-cry.vai-3

Target: Amelia cried again

(BB:2009-03-23)

Recall, however, that the semantic properties of matt-and mattsista'- differ in two major ways. mattsista'- encodes a strict temporal precedence and an identical property requirement where matt- does not. I propose that ista'- is the component of mattsista'- encoding these properties, i.e., the basic meaning of again.

\section{(22) Lexical Entry for ista'-}

$$
\llbracket i s t a^{\prime}-\rrbracket=\lambda \mathrm{P}_{<1,<\mathrm{s}, \mathrm{t}\rangle} \lambda \mathrm{e}:\left[\llbracket \mathrm{MAX} \rrbracket(\mathrm{P})\left(\mathrm{e}^{\prime}\right)=1 \& \mathrm{e}^{\prime}<_{\mathrm{t}} \mathrm{e}\right] . \mathrm{P}(\mathrm{e})
$$

As for the inability of ista'- to occur on its own, I propose that ista'- has stricter requirements than again as to how its anaphoric dependency must be satisfied: while the event variable referred to by again, $e^{\prime}$, may be contextually supplied, extra-linguistically, I propose that the event variable encoded by ist $a^{\prime}-, e^{\prime}$, is parallel to the individual variable associated with English reflexives like himself, in that the variables associated with ista'- and himself must be co-indexed with local linguistic antecedents. The event encoded by matt-, I suggest, acts to satisfy this dependency. I.e., matt-'s event, $e^{\prime \prime}$, is taken as ista'-'s antecedent. This is schematized in (23): 
Deriving full repetition in Blackfoot

(23)
a.
$\mathrm{John}_{\mathrm{i}}$ startled himself
a'. *himself? startled
b. $\quad \operatorname{matt}\left(\mathrm{e}^{\prime \prime}{ }_{\mathrm{i}}\right)$ - ista' $\left(\mathrm{e}_{\mathrm{i}}^{\prime}\right)$ - waasai'ni
b'. *ista'(e'? )-waasai'ni
add-again-cry again-cry

Just as himself must be co-indexed with with a referential expression like John in (23a), the event variable associated with ista'- must be co-indexed with the event variable introduced by matt-. The ungrammaticality of the bare ista'- examples is thus parallel to the ungrammaticality of the un-coindexed reflexive in (23a'). A consequence of the proposed analysis for ista' - is that the events introduced by mattand ista',$- e^{\prime \prime}$ and $e^{\prime}$ respectively, must be co-indexed. I.e., $e^{\prime \prime}$ and $e^{\prime}$ are taken to refer to the same event. ${ }^{10}$ In the following section, I show how this derives mattsista'-'s lack of restitutive readings in default focal contexts.

\subsection{Deriving full repetition}

Consider a derivation where both matt- and ista'- attach to an expression approximating "I closed the door." With such a construction, three events are relevant. First, the asserted event, $e$, which must be an event of the speaker closing the door (24a). Second, the event presupposed by matt-, $e^{\prime \prime}$, which in default contexts, must belong to a poset of events, $E$, derived by applying the sum operation over the set of events exemplifying a VP-focus p-set, as in (24b). This event, $e^{\prime \prime}$, thus must have a form parallel to (24c). Third, the event presupposed by $i s t a{ }^{-}, e^{\prime}$, which we may assume can be interpreted as either repetitive, or restitutive. The event $e^{\prime}$, then, may be as in (24d i), where $e^{\prime}$ is interpreted as an event of the speaker having previously closed the door (the repetitive reading), or $e^{\prime}$ may be as in (24d ii), where $e^{\prime}$ is interpreted as an event(uality) of the door having been previously closed.

10 Notice that this is similar to Beck's (2006) account for blocking restitutive readings in specific focal contexts in English. Beck's analysis, however, is purely pragmatic, which while sufficient to account for the English data, would not be able to account for the more strictly restricted Blackfoot data shown above (i.e., the fact that ista'- cannot occur by itself). 
a. $\quad e=[\mathrm{I}$ closed the door $]$

b. $\quad$ I closed the door, I swam, I sang, I wrote a science-fiction novel... $\}$

c. $\quad e^{\prime \prime}=[$ I VP-ed $]$

d. $\quad e^{\prime}=$

i) [I closed the door before]

(Repetitive)

ii) [The door was closed before]

(Restitutive)

If the events $e^{\prime}$ and $e^{\prime \prime}$ must be co-indexed, as proposed, matt-'s presupposed event $e^{\prime \prime}$ must then be interpreted as the same event as either the event in $(24 \mathrm{~d}$ i), or the event in (24d ii). Under a full-repetition interpretation, this amounts to the equation in (25a), i.e., equating an event of the speaker VP-ing, with an event of the speaker having closed the door before. This is pragmatically coherent; the repetitively interpreted event, $e^{\prime}$, of the speaker having closed the door before, is consistent with the requirement on $e^{\prime \prime}$ that $e^{\prime \prime}$ be of the form (24c). On the other hand, under a restitutive interpretation, this amounts to the equation in (25b), i.e., equating an event of the speaker VP-ing, with an event of the door having been closed before. This, I argue, is pragmatically incoherent, under the assumption that events must have the same argument structure and/or aspectual type, in order to be identified as the same event. I propose that this pragmatic incoherency is what accounts for the original observation from section 1.2, i.e., the observation that Blackfoot mattsista'appears to lack restitutive readings.

$\begin{array}{llll}\text { a. } & e^{\prime \prime}=e^{\prime} & {[\text { I VP-ed }]=[\text { I closed the door before }]} & \text { (Repetitive) } \\ \text { b. } & e^{\prime \prime}=e^{\prime} & \text { [ I VP-ed }]=[\text { The door was closed before }] & \text { (Restitutive) }\end{array}$

\section{Restoring restitutive readings with agent focus}

Here I address the consequences of my analysis; in particular, I address the fact that the account proposed crucially relies on default focus falling on the VP. The prediction is that in contexts forcing focus to be interpreted elsewhere, e.g., on the agent, the pragmatic incoherency ruling out restitutive readings may disappear. This appears to be the case, as shown by (26); when a preceding question overrides default focus so that focus is interpreted on the agent, mattsista'- is felicitous in a restitutive context: 
Deriving full repetition in Blackfoot

(26) Context: We are in a room where the door is closed, but the wind blows it open. I notice that it is starting to get cold, so I get up to go close it, but when I get to the door, I realise that it's already closed. I (S1) ask, and S2 answers:

S1: "Who closed the door?"

S2: Aná Kánaisskinaa mattsistáyookimayi an-wa kánaisskinaa matt-ista'-yookii-m-ayi dem-3 mouse add-again-close.vti-3>0-dtp "Kanaisskinaa (Mouse) closed it again."

The sudden availability of a restitutive reading in different focal contexts can also be seen in (27). First note that (27a) and (27b) were presented in the same restitutive context. The initial utterance in (27a) questions the existence of an agent who caught Abigail, i.e., making salient a set of catching-Abigail events, which vary over agents. Here a felicitous use of mattsista'- is allowed. The initial utterance in (27b) merely makes salient an event where Abigail was caught versus an event(uality) where she was not, however, and the use of mattsista'- is infelicitous.

(27) Context: Last year, Solveiga caught Abigail, a criminal, for the first time. Now I'm the new sheriff in town, and Abigail has escaped jail.

a. S1: "Did anybody catch Abigail?"

S2: Aa, nimattsistayissinototowa anahk Abigail

Aa, ni-matt-ista'-yissinoto-a anahk Abigail

Yes, 1-add-again-catch.vta-loc $>3$ dem Abigail

"Yes, I caught her again."

(BB: 2010-03-24)

b. S1: "Did Abigail get caught?"

S2: \#Aa, nimattsistayissinototowa (anahk Abigail)

Aa, ni-matt-ista'-yissinoto-a (anahk Abigail)

Yes, 1-add-again-catch.vta-loc $>3$ (dem Abigail)

"Yes, I caught her again."
S2': Aa, nikayíssinotowa
(anahk Abigail)
aa, ni-akaa-yissinoto-a
(anahk Abigail)
Yes, 1-perfect-catch.vta-loc $>3$ (dem Abigail)
"Yes, I caught Abigail."

(BB: 2010-04-01)

The availability of restitutive readings in agent-focus contexts is not surprising under the proposed account, although some explanation is required. With focus on the subject, the mattsista'- marked utterance in (26) should have the following properties: 
Asserted event: $e=[$ Kanaisskinaa closed the door $]$

matt-event: $\quad e^{\prime \prime}=$ [AGENT closed the door]

ista'-event: $\quad e^{\prime}=$ [Kanaisskinaa closed the door before](repetitive) OR

$e^{\prime}=[$ The door was closed before](restitutive)

Under the analysis provided here, the events presupposed by matt- and ista'- are identified as the same event. While the matt- event of someone else closing the door and a restitutively presupposed event of the door being closed before differ in their argument structure and aspectual type (disallowing identification), an event of the door being closed before is compatible with being identified as a part of, or sub-event of the matt- event, i.e., its result state sub-event. I suggest that this is what allows for the restitutive meanings in (26)-(27).

\section{Coindexation}

$$
\text { [AGENT caus [closed (the door)]] [closed (the door)] }
$$

This requires that Blackfoot grammatically encodes sub-events for the predicates used in (26)-(27); recall that I have posited that ista'- necessarily take its reference from a grammatically encoded event. Compare the data in (28) to that of (27), where the contexts and focal-setting questions are parallel, however the predicate differs. In (28), unlike (27), the restitutive context with a agent-focus-setting question does not license the use of mattsista'-. This suggests that the lexical predicates differ as to whether they grammatically encode result-state sub-events ${ }^{11}$.

(28) Context: Joel and Jen are in class, but since Joel hasn't slept for ages, he falls asleep. I (S2) tell S1 about this, and S1 asks:

S1: "Did anybody wake up Joel?"

$\begin{array}{lllll}\mathrm{S} 2: & \text { \#Aa, ana Jen máttsistaiksikini } & \text { ani } & \text { Joel } \\ \text { aa, ana Jen matt-ista'-iksikin-yii } & \text { ani } & \text { Joel } \\ \text { yes, dem.3 Jen add-again-wake.vta-3>3”} & \text { dem.3' } & \text { Joel } \\ \text { “\#Yes, Jen woke up Joel again" } & & \end{array}$
"\#Yes, Jen woke up Joel again"

(BB: 2010-03-24)

BB comment: mattsistai' is again, so it doesn't work for that sentence

More significantly, this suggests that the event variables encoded in presuppositions may not be monolithic, but instead may have more internal structure than has been assumed.

11 This reliance on lexical specification also accounts for why the example in 3.3 cannot be similarly analysed. The example in 3.3 involved a focus-abstracted VP, which does not lexically encode a result-state sub-event. 
Deriving full repetition in Blackfoot

\section{Conclusion and issues for further research}

I have argued that Blackfoot's primary method of marking repetition, mattsista'consists of two morphemes matt- and ista'-. I proposed separate denotations for each morpheme, in order to account for their separate distributional and semantic properties, as well as their combined semantic effect. The course of investigating mattand ista'- has provided insight into how Blackfoot, and language in general, may grammatically encodes events. For instance, the availability of restitutive readings in agent-focus contexts follow from the given analysis only if the representation of presupposed events includes internal structure (i.e., sub-events) that the compositional system can access. While several researchers have posited internal structure with respect to the asserted event (cf. Ramchand 2008; Travis 2000; Tenny 1989, 1994), to my knowledge, internal structure is not usually attributed to the event variables lexically encoded in presuppositions. However if, as I have suggested for Blackfoot, the availability of internal structure is lexically specified for each predicate, this specification should hold for any event that the predicate is applied to, whether the event is asserted or presupposed. ${ }^{12}$ Whether internal structure in presupposed entities is a mechanism available to every language, or whether languages differ as to how/whether they structure their presupposed entities, I leave for further research. A final thing to note is that I have implicitly assumed that while matt-'s presupposed event, $e^{\prime \prime}$, can act as an antecedent to ista'-'s presupposed event, $e^{\prime}$, the asserted event, $e$, may not. Similarly, I have assumed that an event quantifier (e.g. aspect, temporal modifiers) may not bind the event variable ista'- introduces. I suggest that this follows from the fact that the relevant event variables/binders are in different domains. I.e., that the events introduced by matt- and ista'- are confined to the presuppositional domain, that the asserted event and event quantifiers like aspect are confined to the domain of assertion, and that dependency relations like binding and co-indexation only operate domain-internally. Thus while the domain of assertion and the domain or presupposition may be more parallel than previously assumed, the two domains must nonetheless be separate.

\section{References}

Bach, Emmon. 1986. The algebra of events. Linguistics and Philosophy 9(1). 5-16. doi:10.1007/BF00627432.

Beck, Sigrid. 2006. Focus on again. Linguistics and Philosophy 29(3). 277-314. doi:10.1007/s10988-005-5794-z.

12 Whether this should be viewed as syntactic structure, or a lexical semantic decomposition, however, I leave up for debate. 
Bonomi, Andrea \& Paolo Casalegno. 1993. Only: Association with focus in event semantics. Natural Language Semantics 2(1). 1-45. doi:10.1007/BF01255430.

Dowty, David R. 1979. Word Meaning and Montague Grammar. Dordrecht, The Netherlands: D. Reidel Publishing Company.

Fabricius-Hansen, Catherine. 2001. Wi(e)der and again(st). In Caroline Fery \& Wolfgang Sternefeld (eds.), Audiatur Vox Sapientiae. A Festschrift for Arnim von Stechow, vol. 52 Studia Gramatica, 101-130. Stanford, CA: Akademie Verlag.

Frantz, Donald G. \& Norma J. Russell. 1989. Blackfoot dictionary of stems, roots and affixes. Toronto, Canada: University of Toronto Press.

Karttunen, Lauri \& Stanley Peters. 1979. Conventional implicature. Syntax and Semantics 1(1). 1-56.

Kratzer, Angelika. 1996. Severing the external argument from the verb. In Johann Rooryck \& Laurie Zaring (eds.), Phrase structure and the lexicon, 75-115. Dordrecht, The Netherlands: Kluwer.

Krifka, Manfred. 1989. Nominal reference, temporal constitution and quantification in event semantics. In Renate Bartsch, Johan F. A. K. van Benthem \& Peter van Emde Boas (eds.), Semantics and Contextual Expression, 75-115. Foris Publications.

Ramchand, Gillian. 2008. Verb Meaning and the Lexicon: A First Phase Syntax, vol. 116 Cambridge Studies in Linguistics. New York: Cambridge University Press.

Rooth, Mats. 1992. A theory of focus interpretation. Natural Language Semantics 1(1). 75-116. doi:10.1007/BF02342617.

von Stechow, Arnim. 1996. The different readings of wieder/again: a structural account. Journal of Semantics 13(2). 101-130. doi:10.1093/jos/13.2.87.

Tenny, Carol. 1989. Gramaticalizing Aspect and Affectedness: MIT dissertation.

Tenny, Carol. 1994. Aspectual Roles and the Syntax-Semantics Interface. Dordrecht, The Netherlands: Kluwer Academic Publishers.

Travis, Lisa. 2000. Event structure in syntax. In Carol Tenny \& James Pustejovsky (eds.), Events as Grammatical Objects: The converging perspectives of lexical semantics and syntax, 145-185. CSLI Publications.

Meagan Louie

UBC Department of Linguistics

Totem Fields Studio

2613 West Mall

Vancouver, B.C., Canada V6T 1Z4

meagan.louie@gmail.com 